\title{
CURRÍCULO MUNDIAL E ENSINO DE CONTABILIDADE: ESTUDO COMPARATIVO DA MATRIZ CURRICULAR DE CIÊNCIAS CONTÁBEIS EM INSTITUIÇÕES DE ENSINO SUPERIOR BRASILEIRAS E FRANCESAS
}

\section{WORLD CURRICULUM AND ACCOUNTANCY TEACHING: A COMPARATIVE STUDY OF ACCOUNTING SCIENCE CURRICULUM MATRICES IN BRAZIL'S AND FRANCE'S HIGHER EDUCATION INSTITUTIONS}

\section{CURRÍCULO MUNDIAL Y ENSEÑANZA DE CONTABILIDAD: ESTUDIO COMPARATIVO DE LA MATRIZ CURRICULAR DE CIENCIAS CONTABLES EN INSTITUCIONES DE ENSEÑANZA SUPERIOR BRASILEÑAS Y FRANCESAS}

Daniel Kouloukoui

Mestre em Contabilidade pela Universidade Federal da Bahia (UFBA), Brasil

danielkoulou@hotmail.com

Antonio Carlos Ribeiro da Silva

Professor adjunto da Universidade Federal da Bahia, Brasil / Doutor em Desenvolvimento Curricular pela Universidade do Minho, Portugal / Ex-Presidente (gestão 2013-2016) da Fundação Visconde de Cairu profacr@hotmail.com

José Ronaldo Bezerra Gabriel

Mestrando em Ciências Contábeis pela Universidade Federal da Bahia (UFBA), Brasil

ronaldogabriel@ig.com.br

Jacilene Oliveira Gonzaga Andrade

Especialista em Contabilidade Gerencial e

Controladoria pela Universidade Federal da Bahia

(UFBA), Brasil / Chefe de Normas e Informações

Gerenciais na Controladoria da Câmara Municipal de

Salvador, Brasil

jacigonzaga@hotmail.com
Contextus

ISSNe 2178-9258

Organização: Comitê Científico Interinstitucional

Editor Científico: Carlos Adriano Santos Gomes

Avaliação: double blind review pelo SEER/OJS

Edição de texto e de layout: Carlos Daniel Andrade

Recebido em 04/09/2016

Aceito em 15/09/2017

$2^{a}$ versão aceita em 02/10/2017

\section{RESUMO}

Este trabalho teve como objetivo analisar e comparar as matrizes curriculares dos cursos de Ciências Contábeis das instituições de ensino superior (IES) da França e do Brasil em relação ao Currículo Mundial (CM), proposto pelo ISAR, grupo de trabalho da Conferência das Nações Unidas sobre Comércio e Desenvolvimento (UNCTAD). Para alcançá-lo, realizou-se uma pesquisa exploratória baseada na análise documental de informações dos cursos de 
graduação em Ciências Contábeis de 10 universidades francesas e 10 brasileiras. Após a organização e classificação dos dados, realizou-se um estudo descritivo para verificar as similaridades entre os currículos dos cursos e o CM. Dentre outros achados, os resultados revelaram que $72 \%$ das IES francesas e $61 \%$ das brasileiras possuem matrizes curriculares correlatas ao CM. Concluiu-se que, de forma geral, as matrizes curriculares das universidades dos dois países estão próximas do CM.

Palavras-Chave: Educação superior em Contabilidade; Currículo Mundial; Matrizes curriculares; Instituições de ensino superior brasileiras e francesas.

\section{ABSTRACT}

The purpose of this work was to analyze the curriculum matrices of Accounting Science undergraduate programs of higher education institutions in France and Brazil as well as to compare them to the World Curriculum (WC), proposed by ISAR, a work group of United Nations Conference on Trade and Development (UNCTAD). To achieve this, an exploratory research was performed based upon a document analysis of institutional information from 10 French and 10 Brazilian universities. After gathering and sorting the data, a descriptive study was carried out to check for similarities between the undergraduate program curricula and the WC. Among other findings, it was disclosed $72 \%$ of the French universities and $61 \%$ of the Brazilian ones had curriculum matrices correlated to the WC. It was concluded that, from an all-encompassing viewpoint, the university curriculum matrices of both countries are close to the WC.

Keywords: Higher Education in Accounting; World Curriculum; Curricular Matrices; Brazilian and French Higher Education Institutions.

\section{RESUMEN}

Este trabajo tuvo como objetivo analizar y comparar las matrices curriculares de los cursos de Ciencias Contables de las instituciones de enseñanza superior (IES) de Francia y Brasil en relación al Currículo Mundial (CM), propuesto por el ISAR, grupo de trabajo de la Conferencia de las Naciones Unidas sobre Comercio y Desarrollo (UNCTAD). Para alcanzarlo, fue realizada una investigación exploratoria con base en el análisis documental de informaciones de los cursos de graduación en Ciencias Contables de 10 universidades francesas y 10 brasileñas. Después de la organización y clasificación de los datos, se aplicó un estudio descriptivo para verificar la similitud entre los currículos de los cursos y el CM. Los resultados revelan, entre otros hallazgos, que el $72 \%$ de las universidades francesa y el $61 \%$ de las brasileñas poseen matrices curriculares correlacionadas al Currículo Mundial. De modo general, se puede concluir que las matrices curriculares de las universidades de los dos países están próximas del Currículo Mundial.

Palabras Clave: Educación superior en Contabilidad; Currículo Mundial; Matrices curriculares; Instituciones de enseñanza superior brasileñas y francesas.

\section{INTRODUÇÃO}

\section{A Contabilidade é uma ciência} social aplicada, daí influenciar e ser fortemente influenciada pelo ambiente em que atua (NIYAMA, 2008; MEYER;
SCOTT, 1991; HOPWOOD, 1983). De acordo com Niyama (2008), valores culturais, tradição histórica, estrutura política, estrutura econômica, crenças e estruturas sociais acabam se refletindo nas práticas contábeis de um país. Entretanto, 
essas variáveis podem resultar na diversidade de interpretações dos fenômenos contábeis de uma nação para outra (SANTOS; DOMINGUES; RIBEIRO, 2013).

Diante do cenário atual de globalização dos negócios, os investidores vão em busca, em qualquer parte do planeta, das melhores oportunidades para alocarem seus recursos. Eles se servem de informações contidas nos relatórios contábeis para tomar decisões sobre seus investimentos. Nesse contexto, a importância da informação contábil ultrapassou as fronteiras, deixando de ter sua utilidade limitada ao campo doméstico para servir de instrumento para tomadas de decisão em nível internacional (NIYAMA, 2008).

Tais fatores trouxeram consigo a necessidade de uma linguagem contábil a mais compartilhada possível pelos agentes econômicos e usuários da Contabilidade em todo o mundo, o que levou à criação do chamado Currículo Mundial (CM). Esse documento foi desenvolvido pelo Grupo de Trabalho Intergovernamental de Peritos em Padrões Internacionais de Contabilidade (ISAR), subordinado à Conferência das Nações Unidas sobre Comércio e Desenvolvimento (UNCTAD), ligada, por sua vez, à Organização das Nações Unidas (ONU).
$\mathrm{O}$ documento tem como principal objetivo servir de guia na formulação dos currículos de ensino superior da Contabilidade e harmonizar o conhecimento contábil no mundo. Constitui-se, portanto, em um dos resultados da internacionalização do fluxo de capitais, paralelo ao desenvolvimento acelerado da alta tecnologia. Com finalidade semelhante à do CM, também foram criadas, por exemplo, as Normas Internacionais de Contabilidade (IRFS), pelo International Accountant Standards Board (IASB), com o intuito de harmonizar técnicas contábeis e permitir a comparação entre os fenômenos econômicos retratados pela Ciência Contábil.

Na opinião de Erfurth e Domingues (2013), o CM se destaca ao propor-se preencher a lacuna de uma referência para as qualificações do profissional de Contabilidade. Com efeito, ele apresenta de maneira detalhada os conteúdos necessários para que o contador possa estar de acordo com as normas internacionais da sua profissão. Preocupados com a capacidade das instituições de ensino superior (IES) de formar profissionais contábeis aptos a atender as novas demandas do mercado, os organismos internacionais têm trabalhado para elaborar um programa de estudos de Contabilidade que sirva de referência mundial. A 
existência de contadores qualificados depende do amplo conhecimento e da utilização de normas internacionais.

No Brasil, por exemplo, as diretrizes para o ensino da Contabilidade contidas na Resolução CNE/CES 10/2004 salientam que as matrizes curriculares devem ter componentes mínimos de conteúdos e que cada IES deve direcionar o seu currículo respeitando essas orientações. Isso pode ser apontado como um avanço no modelo brasileiro. Segundo a resolução, as instituições devem adequar seus currículos seguindo as diretrizes estabelecidas e considerando suas realidades.

Caso determinados países não se adaptem às normas internacionais, poderão ficar distantes e em desvantagem em relação aos demais. Erfurth e Domingues (2013) salientam a gravidade dessa discrepância para os países em desenvolvimento, ao não pautarem nesse cuidado a orientação educacional aos novos profissionais da área contábil.

Seguindo o mesmo raciocínio, Franco (1999) destaca como preocupação da UNCTAD o efeito desse processo de internacionalização contábil sobre os países em desenvolvimento, que diferem significativamente dos desenvolvidos quanto à profissão contábil. Sob esse prisma, questiona-se: qual é o grau de proximidade das matrizes curriculares das universidades do Brasil e das universidades dos países desenvolvidos em relação ao CM?

Para responder a questão, a presente pesquisa analisou e comparou a matriz curricular dos cursos de Ciências Contábeis de universidades francesas e brasileiras em relação aos conteúdos mínimos sugeridos pelo modelo da UNCTAD para o ensino superior em Contabilidade. Dessa forma, contribui-se para a literatura sobre educação contábil, mais particularmente sobre a matriz curricular dos cursos de Ciências Contábeis, e amplia-se o conhecimento obtido de trabalhos anteriores. Os achados podem trazer novidades, estimulando discussões acerca da matriz curricular e promovendo uma visão mais abrangente dos conteúdos programáticos de Ciências Contábeis nos países em desenvolvimento (Brasil) e nos desenvolvidos (França).

\section{FUNDAMENTAÇÃO TEÓRICA}

\subsection{Currículo Mundial de Contabilidade}

Currículo pode ser entendido como um documento que compõe o mínimo de disciplinas exigidas de um graduando para sua formação. $\mathrm{Na}$ opinião de Tcheou (2002, p. 77), “é um conjunto de disciplinas, organizadas em sequência 
lógica de conteúdos, que busca atender às necessidades e às expectativas da sociedade em relação ao indivíduo a ser formado por ela".

De acordo com Erfurth e Domingues (2013), o crescimento da economia internacional traz consigo a necessidade de uma linguagem única que possa viabilizar o processo de comunicação entre os agentes econômicos, bem como a comparação das empresas e investimentos dos diferentes países no mundo. Contudo, de um país para outro, há diferenças na Contabilidade e, consequentemente, na formação do profissional contábil, o que pode ocasionar problemas, por exemplo, na interpretação de duas realidades econômicas distintas. Foi com base nisso que o ISAR da UNCTAD desenvolveram o já mencionado CM: um guia ou ponto de partida para os países na elaboração do seu próprio currículo.

Tal modelo envolve uma descrição das áreas técnicas que um aluno deve dominar para se tornar um contador profissional. Faz parte de um esforço maior de criar um referencial para as qualificações profissionais voltadas à economia global, abrangendo conhecimentos básicos gerais e habilidades relevantes para um mundo interdependente (UNCTAD 1999, p. 1). globalização nas mais distintas áreas do cenário mundial, promovendo o entrelaçamento de todas as esferas sociais, culturais e econômicas e revelando uma tendência cada vez maior de uniformizar o conhecimento. Isso se reflete claramente na prática das Ciências Contábeis pelo mundo. Diante desse cenário, Ricco e Sakata (2004) destacam que as inúmeras transformações na economia local de muitos países têm gerado um enorme esforço das instituições de ensino superior (IES) nacionais e estrangeiras para harmonizar os modelos econômicos. Conforme apontam Czesnat, Cunha e Domingues (2009), essa tarefa está na origem do $\mathrm{CM}$, projeto visto como saída para aperfeiçoar os trâmites que envolvem o relacionamento comercial no âmbito internacional.

No entanto, vale ressaltar que as IES não são obrigadas a adotar esse projeto, que apenas sugere a inclusão de módulos de disciplinas capazes de garantir mais qualidade ao ensino contábil, cabendo a cada instituição decidir quanto a sua adoção ou não (CAVALCANTE et al., 2014).

Conforme discutido na UNCTAD, o projeto proposto compõe-se de quatro blocos de conhecimentos, conforme Quadro 1.

$$
\text { É perceptível o impacto da }
$$


Quadro 1 - Blocos de conhecimento da UNCTAD

\begin{tabular}{|c|c|c|c|}
\hline $\begin{array}{l}\text { 1.Conhecimentos } \\
\text { administrativos e } \\
\text { organizacionais }\end{array}$ & $\begin{array}{l}\text { 2. Tecnologia de } \\
\text { informação }\end{array}$ & $\begin{array}{l}\text { 3. Conhecimentos de } \\
\text { contabilidade e assuntos afins }\end{array}$ & 4.Conhecimentos gerais \\
\hline $\begin{array}{l}\text { 1.1 Economia. } \\
\text { 1.2 Métodos quantitativos e } \\
\text { estatística para administração. } \\
\text { 1.3 Políticas gerais } \\
\text { administrativas, } \\
\text { estruturas básicas } \\
\text { organizacionais. } \\
\text { 1.4 Funções e práticas } \\
\text { gerenciais, comportamento } \\
\text { organizacional, a função do } \\
\text { marketing em administração e } \\
\text { princípios de negócios } \\
\text { internacionais. } \\
\text { 1.5 Módulo de gestão e } \\
\text { estratégia organizacional. }\end{array}$ & \begin{tabular}{|l} 
2.1 Tecnologia de informação \\
(TI). \\
2.1.1 (TI) conceitos para \\
sistemas administrativos. \\
2.1.2 Controle interno: sistemas \\
informatizados de gestão. \\
2.1.3 Desenvolvimento de \\
padrões e práticas para a \\
administração de sistemas. \\
2.1.4 Gestão, implementação e \\
uso de TI. \\
2.1.5 Gestão da segurança em \\
informação. \\
2.1.6 Inteligência artificial, \\
expert systems, fuzzy logic etc. \\
2.1.7 Comércio eletrônico.
\end{tabular} & $\begin{array}{l}\text { 3.1 Contabilidade básica e } \\
\text { preparação de relatórios } \\
\text { financeiros, a profissão contábil, } \\
\text { padrões contábeis internacionais. } \\
\text { 3.2 Práticas contábeis e financeiras } \\
\text { avançadas. } \\
\text { 3.3 Princípios de relatórios } \\
\text { financeiros avançados. } \\
\text { 3.4 Contabilidade Gerencial. } \\
\text { 3.5 Contabilidade Gerencial: } \\
\text { informação para planejamento, } \\
\text { tomada de decisão e controle. } \\
\text { 3.6 Tributação. } \\
\text { 3.7 Legislação comercial. } \\
\text { 3.8 Fundamentos de auditoria. } \\
\text { 3.9 Auditoria: conceitos } \\
\text { avançados. } \\
\text { 3.10 Finanças e gestão financeira. }\end{array}$ & $\begin{array}{l}\text { 4.1 História e religião. } \\
\text { 4.2 Comportamento } \\
\text { humano/Psicologia. } \\
\text { 4.3 Economia local } \\
\text { 4.4 Metodologia de pesquisa. } \\
\text { 4.5 Artes e Literatura. } \\
\text { 4.6 Ética. } \\
\text { 4.7 Filosofia. } \\
\text { 4.8 Comunicação oral. } \\
\text { 4.9 Línguas. } \\
\text { 4.10 Experiência } \\
\text { profissional/Estágio. }\end{array}$ \\
\hline
\end{tabular}

Fonte: adaptado de Riccio e Sakata (2004).

Segundo Hendriksen e Van Breda (2014, p. 29), a Contabilidade é considerada a linguagem dos negócios, de modo que o acelerado crescimento das relações comerciais mundiais evidenciou a necessidade de diminuir as diferenças naquela linguagem. $\mathrm{O}$ crescimento se deu, conforme Shixiu (2008), por causa do avanço na tecnologia e nas técnicas de comunicação, que reduziu os custos de transporte e as barreiras comerciais. Desse modo, a falta de harmonia entre os procedimentos contábeis de todos os países, segundo Martins (2004), incentiva o descrédito da informação contábil, retardando e encarecendo as negociações por exigir muitas vezes regras contábeis diferentes para mensurar o mesmo evento.

De acordo com Leite (2002), os países que adotam normas contábeis padronizadas tornam suas operações mais transparentes e menos arriscadas, o que acaba por atrair mais investidores. Dessa maneira, a educação em Contabilidade de todas as IES está gradualmente se mobilizando para adotar um currículo padronizado em nível internacional, buscando maior eficiência e integração (BONK; SMITH, 1998).

Essa proposta de um ensino contábil pareado com as necessidades de um mundo cada vez mais unificado promoverá, dentre outras ações, o desenvolvimento de competências que permitirão ao profissional da área integrar o ambiente particular de suas experiências a uma complexa esfera global. Também provocará a aplicação de ferramentas que possibilitem o exercício da Contabilidade por meio de uma nova consciência, mais integrada às necessidades e idiossincrasias de cada região, adotando medidas mais 
eficazes para transformar a realidade em prol do desenvolvimento coletivo.

O objetivo principal do CM é, então, fornecer conteúdos disciplinares básicos para a formação de profissionais capazes de atuarem em seu país e no exterior. Segundo a UNCTAD (1999), o currículo detalhado é apenas o ponto de partida para um país que pretenda conciliar seu sistema educacional às necessidades globais.

O CM deve ser lido com três advertências em mente. Em primeiro lugar, como ele se destina a servir de guia para o conteúdo técnico da formação profissional, deve distinguir o conhecimento geral das habilidades básicas que os candidatos precisam para se destacar em uma economia interdependente. Em segundo lugar, há, pelo menos, duas abordagens distintas para a formação global de Contabilidade, sendo uma delas prescritiva, na medida em que especifica as habilidades necessárias do ensino geral que os contabilistas precisam desenvolver. É considerada como uma abordagem "input". A outra abordagem baseia-se no conceito de competência: a capacidade de realizar atividades dentro de uma ocupação ou função para os padrões esperados no emprego. Tal abordagem também especifica as competências de que os profissionais precisam para destacar-se no mercado do trabalho. A terceira e última advertência decorre da compreensão do CM como mero ponto de partida para um sistema educacional que atenda às necessidades globais (UNCTAD, 1999). Cada país deve desenvolver os conteúdos programáticos correspondentes, determinar o tempo a ser gasto em cada módulo e adaptar o conteúdo às necessidades nacionais ou regionais.

\subsection{Curso de Ciências Contábeis no Brasil}

No Brasil, o ensino de Ciências Contábeis originou-se nas Escolas de Comércio (SANTOS; DOMINGUES; RIBEIRO, 2013). A Aula de Comércio foi oficialmente instituída no Brasil por meio do Alvará de 15 de julho de 1809 com a criação da Aula de Comércio da Corte no Rio de Janeiro. Em 1894, já havia várias aulas de comércio com a finalidade específica de formar "guarda-livros". Em 1905, o Decreto Federal $\mathrm{n}^{\mathbf{o}} 1.339$ reconheceu os diplomas expedidos pela escola Álvares Penteado.

Segundo Leite (2005), as escolas de comércio representaram os primeiros passos para o surgimento de um bom número de cursos de nível médio e superior no país, dentre estes o curso técnico em Contabilidade e o superior de Ciências Contábeis, que surgiram algumas décadas depois, em 1946. O Decreto $\mathrm{n}^{\circ}$ 
20.158 de 1931 reorganizou o ensino comercial, dividindo-o em níveis técnico, superior e propedêutico (SANTOS; DOMINGUES; RIBEIRO, 2013).

Entre 1931 e 1961 tivemos mais de 7 decretos ligados a organização e regulamentação dos cursos técnicos e superiores em Contabilidade. Em 1961, foi criada a Lei de Diretrizes e Bases da Educação Nacional, revisada pela Lei $n^{\circ}$ 9.394, de 1996. A Resolução CNE no $10 / 2004$ instituiu as diretrizes que os currículos dos cursos de Ciências Contábeis do Brasil devem seguir. $\mathrm{O}$ artigo $3^{\circ}$ estabelece que o profissional deve ser capacitado a: (1) compreender as questões científicas, técnicas, sociais, econômicas e financeiras em âmbito nacional e internacional e nos diferentes modelos de organização; (2) apresentar pleno domínio das responsabilidades funcionais envolvendo apurações, auditorias, perícias, arbitragens, noções de atividades atuariais e de quantificações de informações financeiras, patrimoniais e governamentais, com a plena utilização de inovações tecnológicas; (3) revelar capacidade crítico-analítica de avaliação, quanto às implicações organizacionais do advento da tecnologia da informação.

\subsection{Revisão da literatura sobre o CM}

Vários estudos foram realizados com o intuito de verificar até que ponto os currículos dos cursos de Ciências Contábeis são próximos ao CM. No cenário internacional, Rizvi et al. (1998) analisaram o conteúdo do currículo necessário para a formação do contador em função da globalização da economia. Posteriormente, Calhoun e Walsh (2000) compararam as matrizes curriculares dos programas do IFAC (IEG9), da UNCTAD e da AACSB. Os achados demonstraram que existe similaridade das matrizes, apesar de pequenas diferenças de conteúdo.

Ripoll e Rosa (2010), por sua vez, realizaram um estudo comparativo das matrizes curriculares de universidades brasileiras, espanholas e portuguesas. O objetivo principal de tal análise foi identificar se os graduados em Contabilidade estavam preparados nos seguintes aspectos: conformidade com as variáveis de formação de conhecimento e habilidades sociais; conhecimento da formação profissional; avaliação da competência profissional; aquisição de experiência profissional e de educação continuada, instituído pelo ISAR/UNCTAD e IFAC, para atuar no mercado global. Os autores concluíram que os graduados não estão preparados de 
acordo com os requisitos sugeridos pelo ISAR/UNCTAD e IFAC para realizarem suas atividades em uma economia globalizada.

No panorama nacional, Riccio e Sakata (2004) contrastaram as matrizes curriculares dos cursos de Ciências Contábeis de universidades do Brasil e de Portugal. Para tanto, coletaram dados de 25 universidades brasileiras e 25 universidades portuguesas. Como resultado, analisando-se o posicionamento em relação ao $\mathrm{CM}$, observou-se que o bloco de conhecimentos administrativos e organizacionais - tanto do Brasil como de Portugal - é o que apresentou maior aproximação. $\mathrm{O}$ que mais se distanciou foi o bloco de conhecimentos gerais. Outra característica foi a quantidade ainda baixa de disciplinas de tecnologia de informação na maioria das grades curriculares.

De forma análoga, Mulatinho (2007), em sua dissertação de mestrado, comparou, nos cursos de graduação das universidades federais da Paraíba, Pernambuco e Rio Grande do Norte, tanto as matrizes curriculares, quanto a percepção dos docentes com o Programa Mundial de Estudos em Contabilidade (PMEC), proposto pelo ISAR/UNCTAD. Os achados mostraram que as instituições federais de ensino (IFES) estudadas contemplam as disciplinas do PMEC, exceto nas áreas: TI; tópicos internacionais; contabilidade social, ambiental e internacional; e línguas estrangeiras. Czesnat, Cunha e Domingues (2009), por sua vez, cotejaram as matrizes curriculares de Ciências Contábeis de 12 universidades de Santa Catarina. Os resultados apontaram que $88,27 \%$ das disciplinas estão adaptadas ao $\mathrm{CM}$; no entanto, apenas quatro das universidades pesquisadas ofertam Contabilidade Internacional como disciplina obrigatória.

Com o intuito de comparar as grades curriculares de Contabilidade em universidades paranaenses em relação ao CM, Santos, Domingues e Ribeiro (2013), selecionaram 72 instituições: 57 privadas e 15 públicas. Revelou-se, dentre outros achados, que $88,38 \%$ das disciplinas são correlatas ao CM. Os resultados foram analisados sob a perspectiva da Teoria Institucional, por meio da qual se justifica a similaridade encontrada.

Segantini et al. (2013) se propuseram analisar, quanto à adequação ao $\mathrm{CM}$, os currículos de Ciências Contábeis de quatro universidades do MERCOSUL, sendo uma de cada país. As selecionadas foram: Facultad de Ciencias Económicas de la Universidad de Buenos Aires (Argentina); Faculdade de Economia, Administração e Contabilidade da universidade de São Paulo (Brasil); Universidad Nacional de Asunción 
(Paraguai); e Facultad de Ciencias Económicas y de Administración de la Universidad de la República (Uruguai). Os resultados indicam que a similaridade entre os currículos das quatro universidades selecionadas com o CM é alta: em média, $76,71 \%$.

Com base nos trabalhos acima citados, percebe-se que, apesar de existirem estudos sobre a temática, a maioria deles se concentraram na comparação: entre estados brasileiros, a exemplo de Mulatinho (2007), entre IES do mesmo estado (SANTOS; DOMINGUES; RIBEIRO (2013); CZESNAT; CUNHA; DOMINGUES (2009), entre o Brasil e outros países do Mercosul (SEGANTINI et al., 2013) e, por fim, entre Brasil e Portugal, conforme a pesquisa de Riccio e Sakata (2004).

Todos esses estudos compararam duas extremidades de realidades de certo modo similares. Por exemplo, mesmo comparando currículos de diferentes estados brasileiros, há realidades comuns, uma vez que se trata de um mesmo país. Também há similaridades na comparação entre o Brasil e vizinhos do Mercosul, todos compartilhando a mesma região e, guardadas as proporções, o estágio não desenvolvido da economia. Além disso, a pesquisa que analisou o Brasil e Portugal (RICCIO; SAKATA, 2004) também comparou duas realidades que de alguma forma apresentam semelhanças. Devido à relação de colonização, os dois países ainda guardam uma relação de cooperação cultural e educacional.

Portanto, a ideia que move o presente estudo é comparar a matriz curricular do Brasil com a de um país de realidade muito distinta, ou seja, um país desenvolvido, com língua não ibérica. $\mathrm{Na}$ literatura, não foi possível localizar um estudo do gênero. Conforme Franco (1999), a UNCTAD preocupa-se com a diversidade da profissão contábil entre os países desenvolvidos e aqueles em desenvolvimento. É nesse aspecto em que residem o diferencial e a contribuição deste estudo.

\section{PROCEDIMENTOS METODOLÓGICOS}

De um ponto de vista geral, esta pesquisa possui caráter exploratório e descritivo (ANDRADE, 2005), na medida em que busca observar, registrar, analisar, classificar e interpretar os fatos de seu escopo sem interferir nos resultados. Os fenômenos do mundo físico e humano são estudados, mas não manipulados pelo pesquisador. Além disso, como em qualquer pesquisa descritiva, visa-se aqui expor as características de determinada população (GIL, 2010), identificando-se 
possíveis relações entre variáveis pertinentes.

Aplicando essa abordagem ao objetivo de comparar, com a proposta da UNCTAD, as matrizes curriculares das instituições analisadas, foi verificado se cada uma destas oferecia os conteúdos mínimos de cada um dos quatro blocos de conhecimento. Em seguida, procedeu-se à computação de totais e médias relativos aos países sede das instituições.

\subsection{População e composição da amostra}

Já se mencionou como motivação para escolher a França nesta pesquisa o fato de ser ela um país desenvolvido com idioma não ibérico. Com efeito, a revista Exame ${ }^{\circledR}$ publicou uma reportagem em 2015 reproduzindo estudo do Programa das Nações Unidas para o Desenvolvimento (Pnud). Ali foi divulgada uma lista de países ordenada em função de seus índices de desenvolvimento humano (IDH). A França ocupa a $22^{\mathrm{a}}$ posição, com os seguintes dados:

- IDH: 0,888;

- Expectativa de vida no nascimento: 82,2;

- Expectativa de anos de escolaridade: 16

- Anos de escolaridade: 11,1 ;

- PIB per capita: 38.056 .
Além disso, um dos autores do presente estudo é nativo de um país cujo principal idioma é o francês. Como isso facilitaria bastante a coleta, a organização e a interpretação dos dados, foi aquele o país escolhido para a análise comparativa.

O universo foi composto por todas as IES brasileiras e francesas com websites disponíveis. Para a obtenção dos dados, foi realizado primeiramente um acesso ao sítio do ministério de educação de cada país onde foi possível encontrar a lista de todas as instituições de ensino superior (IES). Encontraram-se no Brasil mais de 1600 cursos de Ciências Contábeis em universidades e em institutos de ensino superior, públicos e privados, (portal.mec.gov.br/instituicoescredenciadas-sp-1781541355).

$\mathrm{Na}$ plataforma do Ministério da Educação da França (www.enseignementsup-

recherche.gouv.fr/), foi possível localizar apenas 73 instituições públicas e privadas que oferecem curso de Ciências Econômicas e de Gestão disponibilizados. Cumpre esclarecer que, contrariamente ao que se observa no Brasil, não existem na França cursos denominados de graduação em Ciências Contábeis. Em vez disso, há cursos de graduação em Ciências Econômicas e Gestão, e, numa das especialidades de Gestão, encontra-se a Contabilidade. 
Em seguida, realizou-se um acesso ao sítio de cada universidade da França com o propósito de coletar a matriz curricular. Nessa etapa, foram encontradas apenas $\quad 10 \quad$ instituições que disponibilizaram os conteúdos programáticos em formato adequado para a construção desse trabalho. Assim, para efeito de comparação entre os dois países, foram selecionadas, aleatoriamente, também 10 instituições de curso de Ciências Contábeis no Brasil para que o número de universidade dos dois países fosse igual. A escolha aleatória das 10 universidades brasileiras foi feita mediante a função "ALEATÓRIOENTRE" disponível no Excel. Ou seja, com a lista de todas as universidades brasileiras de Ciências Contábeis, foi utilizada a ferramenta mencionada para a escolha das 10 universidades. Dessa forma, todas as universidades tiveram a mesma chance de ser escolhida.

Por fim, a amostra foi composta por 20 cursos de Ciências Contábeis em universidades e faculdades do Brasil e da França (10 universidades para cada país). A lista das universidades é apresentada no Quadro 2.

Quadro 2 - Amostra das universidades da França e do Brasil

\begin{tabular}{|l|l|}
\hline FRANÇA & BRASIL \\
\hline 1) Université Aix Marseille & 1) Universidade de São Paulo \\
\hline 2) Université d'Angers & 2) Universidade de São Paulo de Ribeirão Preto \\
\hline 3) Université des Antilles et de la Guyane & 3) Pontifícia Universidade Católica São Paulo \\
\hline 4) Université de Franche-Comté & 4) Universidade de Minas Gerais \\
\hline 5) Université de Montpelier 1 & 5) Universidade Federal da Bahia \\
\hline 6) Université de Nantes & 6) Universidade Federal do Ceará \\
\hline 7) Université de Paris 1 & 7) Universidade Federal do Rio Grande do Sul \\
\hline 8) Université de Picardie & 8) Universidade Federal de Santa Catarina \\
\hline 9) Université de Strasbourg & 9) Fundação Visconde de Cairu \\
\hline 10) Université de Reims & 10) Universidade Federal do Rio de Janeiro \\
\hline
\end{tabular}

Fonte: dados da pesquisa (2015).

É importante salientar que o presente estudo não tem como objetivo investigar os melhores cursos de Ciências Contábeis nem tampouco a qualidade de ensino das universidades. Trata-se, na verdade, tão somente de uma comparação entre as matrizes curriculares e o CM.

\subsection{Modelo da pesquisa}

O presente estudo buscou analisar e identificar os pontos comuns mensurados em percentagem e/ou em valores agregados dos componentes de matrizes curriculares dos cursos de Ciências Contábeis em universidades do Brasil e da 
França. O passo seguinte consistiu em examinar, assim como no trabalho de Riccio e Sakata (2004), até que ponto as matrizes curriculares estão alinhadas com as recomendações sugeridas pelas instituições internacionais.

Com base no Quadro $1-$ apresentado na seção 2.1 e referente aos quatro blocos de conhecimento previstos pelo ISAR da UNCTAD (1999) -, as matrizes curriculares de cada curso foram analisadas e classificadas de acordo os blocos de conhecimento: 1 . conhecimentos administrativos e organizacionais (CAO); 2. tecnologia de informação (TI); 3 . conhecimentos de contabilidade e assuntos afins (CC); 4. conhecimentos gerais (CG).

Para atingir o objetivo deste estudo, após a classificação de cada grade curricular por blocos, calculou-se a percentagem de cada um destes em relação ao total. $\mathrm{O}$ mesmo procedimento foi feito para o CM. Assim, as percentagens obtidas de cada grade foram confrontadas com as do CM.

\subsection{Enquadramento e limitações da pesquisa}

Este trabalho apresentou inúmeras limitações que precisam ser devidamente destacadas. Uma delas, como na maioria dos estudos, é o tamanho da amostra. Apenas 10 universidades francesas de cursos de Contabilidade disponibilizaram dados suficientes para a realização do presente estudo, por essa razão, foram selecionadas também 10 universidades no Brasil para que a amostra fosse igual nos dois países, facilitando assim as comparações. Para as demais, foi enviado e-mail para solicitar a matriz curricular junto às IES francesas, porém nenhuma respondeu.

\section{APRESENTAÇÃO E ANÁLISE DOS RESULTADOS}

Inicialmente, realizou-se
estatística descritiva de todas as
universidades, subdivididas por país, de
acordo com os quatro blocos de
conhecimento
propostos pelo
ISAR/UNCTAD (1999). No caso brasileiro (Tabela 1), observa-se, por exemplo, uma média de quase 25 disciplinas de Contabilidade, com pequenos desvios. $\mathrm{O}$ bloco de conhecimentos gerais, com média de quase 9 disciplinas por universidade, apresentou variação maior: enquanto algumas instituições da amostra oferecem uma única disciplina, uma chega a 17. 
Daniel Kouloukoui, Antonio Carlos Ribeiro da Silva, José Ronaldo Bezerra Gabriel, Jacilene Oliveira Gonzaga Andrade

Tabela 1 - Quantidade de disciplinas por bloco de conhecimento e por universidade brasileira

\begin{tabular}{|l|r|r|r|r|r|r|r|r|r|r|r|}
\hline Universidade/Faculdade & 1 & 2 & 3 & 4 & 5 & 6 & 7 & 8 & 9 & 10 & MÉDIA \\
\hline 1. Conhecimentos administrativos e organizacionais & 14 & 10 & 10 & 10 & 6 & 11 & 8 & 9 & 7 & 13 & 9,8 \\
\hline 2. Tecnologia de informação & 1 & 1 & 1 & 2 & 1 & 2 & 1 & 3 & 2 & 0 & 1,4 \\
\hline 3. Conhecimentos de Contabilidade e assuntos afins & 23 & 32 & 28 & 22 & 25 & 25 & 27 & 19 & 29 & 13 & 24,3 \\
\hline 4. Conhecimentos gerais & 8 & 11 & 1 & 3 & 7 & 6 & 10 & 7 & 17 & 16 & 8,6 \\
\hline TOTAL & 46 & 54 & 40 & 37 & 39 & 44 & 46 & 38 & 55 & 42 & 44,1 \\
\hline
\end{tabular}

Fonte: dados da pesquisa (2015).

Quanto às IES francesas (Tabela 2), o bloco de conhecimentos administrativos e organizacionais é representado, em média, por quase 21 disciplinas por instituição. Nele não existem grandes variações: todas as universidades ofertam disciplinas de maneira moderada. É no bloco de conhecimentos gerais - com média de 4 disciplinas por curso - que as universidades apresentam maior variação.

Tabela 2-Quantidade de disciplinas por bloco de conhecimento e por universidade francesa

\begin{tabular}{|l|r|r|r|r|r|r|r|r|r|r|r|}
\hline FRANÇA & & & & & & & & \\
\hline Universidade/Faculdade & 1 & 2 & 3 & 4 & 5 & 6 & 7 & 8 & 9 & 10 & MÉDIA \\
\hline 1. Conhecimentos administrativos e organizacionais & 22 & 20 & 24 & 23 & 15 & 25 & 14 & 19 & 24 & 22 & 20,8 \\
\hline 2. Tecnologia de informação & 3 & 3 & 5 & 3 & 4 & 3 & 2 & 3 & 3 & 5 & 3,4 \\
\hline 3. Conhecimentos de Contabilidade e assuntos afins & 12 & 16 & 8 & 16 & 14 & 8 & 13 & 15 & 11 & 18 & 13,1 \\
\hline 4. Conhecimentos gerais & 12 & 13 & 18 & 17 & 24 & 7 & 11 & 20 & 6 & 15 & 14,3 \\
\hline TOTAL & 49 & 52 & 55 & 59 & 57 & 43 & 40 & 57 & 44 & 60 & 51,6 \\
\hline
\end{tabular}

Fonte: dados da pesquisa (2015).

Considerando o objetivo principal do presente estudo, as disciplinas das 20 universidades foram classificadas de acordo com sua distribuição entre os quatro blocos de conhecimento do padrão
ISAR/UNCTAD, conforme se pode observar na Tabela 3, com dados apresentados em pontos percentuais.

Tabela 3 - Disciplinas por bloco de conhecimento: proporções do Brasil, da França e da UNCTAD

\begin{tabular}{l|c|c|c}
\hline BLOCOS DE CONHECIMENTOS & BRASIL & FRANÇA & UNCTAD \\
\hline \hline 1. Conhecimentos administrativos e organizacionais & $23 \%$ & $40 \%$ & $30 \%$ \\
\hline 2. Tecnologia de informação & $3 \%$ & $7 \%$ & $7 \%$ \\
\hline 3. Conhecimentos de Contabilidade e assuntos afins & $55 \%$ & $25 \%$ & $50 \%$ \\
\hline 4. Conhecimentos gerais & $19 \%$ & $28 \%$ & $13 \%$ \\
\hline
\end{tabular}

Fonte: dados da pesquisa (2015).

As disciplinas oferecidas pelas IES francesas concentram-se no bloco de conhecimentos administrativos e organizacionais $(40 \%)$, enquanto, no Brasil, é o bloco de Contabilidade o mais representado (mais de 50\%). De forma genérica, a França distribui suas disciplinas de modo mais próximo ao do CM. Porém, esses valores não podem ser considerados de forma global, fazendo-se necessário analisá-los de maneira mais detalhada, em função das várias universidades, tal como nos gráficos de 1 a 4 . Os valores alinhados verticalmente à esquerda se referem às 
quantidades de disciplinas do bloco em questão; os números de 1 a 10, alinhados horizontalmente, representam as universidades da amostra.

Gráfico 1 - Conhecimentos organizacionais: comparação entre Brasil, França e UNCTAD

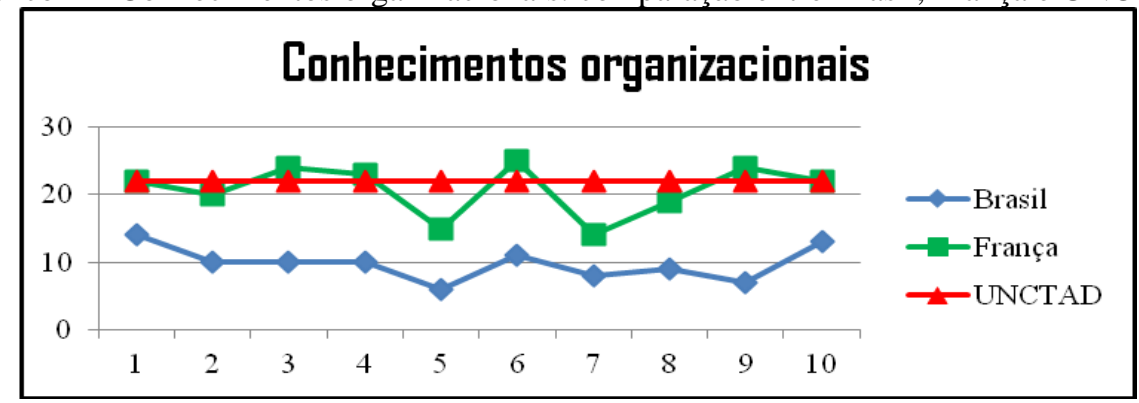

Fonte: dados da pesquisa 2015.

O Gráfico 1 demonstra que, quanto às disciplinas de conhecimentos administrativos e organizacionais, as instituições francesas estão mais próximas do padrão proposto pela UNCTAD. Esse bloco é composto por disciplinas tais como: Economia, Macroeconomia, Microeconomia, Matemática, Estatística, Gestão etc. O resultado sugere que um profissional formado na França está teoricamente mais preparado nos conhecimentos administrativos e organizacionais para atender as exigências do mercado globalizado.

No que tange ao bloco de TI, a França também se revelou mais próxima do padrão da UNCTAD, conforme apresentado no Gráfico 2. Nesse bloco, o Brasil se distanciou do CM de maneira destacada em relação à França, o que pode ser interpretado como reflexo do fato de a França ser um país desenvolvido, com tecnologia mais avançada que no Brasil e um volume muito maior de sistemas informatizados.

Gráfico 2 - Tecnologia de informação: comparação entre Brasil, França e UNCTAD

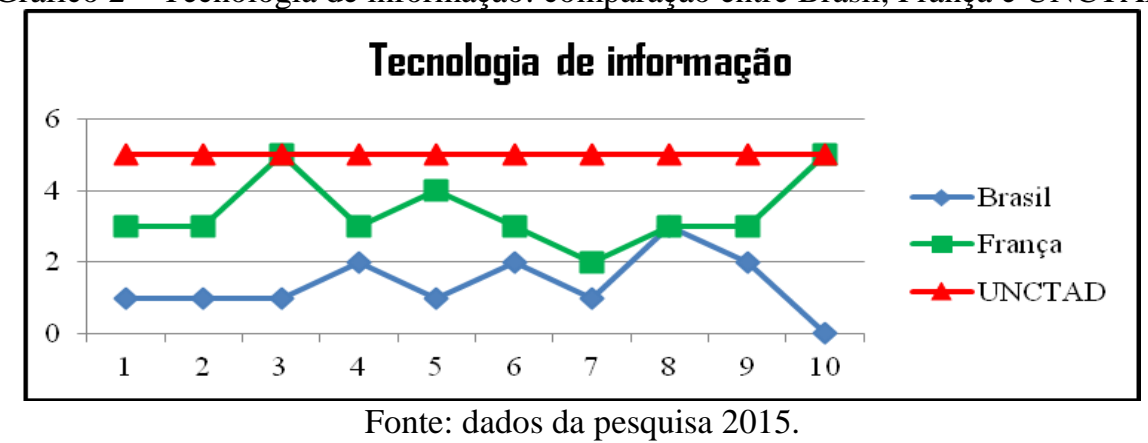

Quanto ao bloco de conhecimentos de Contabilidade e assuntos afins (Gráfico 3), é o Brasil que se encontra mais próximo do sugerido no documento da UNCTAD. Por fim, no que diz respeito ao bloco de conhecimentos gerais (Gráfico 4), ambos 
Daniel Kouloukoui, Antonio Carlos Ribeiro da Silva, José Ronaldo Bezerra Gabriel, Jacilene Oliveira Gonzaga Andrade

os países estão próximos do padrão disciplinas do que o documento da ISAR/UNCTAD. Porém, a França UNCTAD nesse bloco. O Brasil se apresentou um número maior de aproximou com $89 \%$ de similaridade.

Gráfico 3 - Contabilidade: comparação entre Brasil, França e UNCTAD

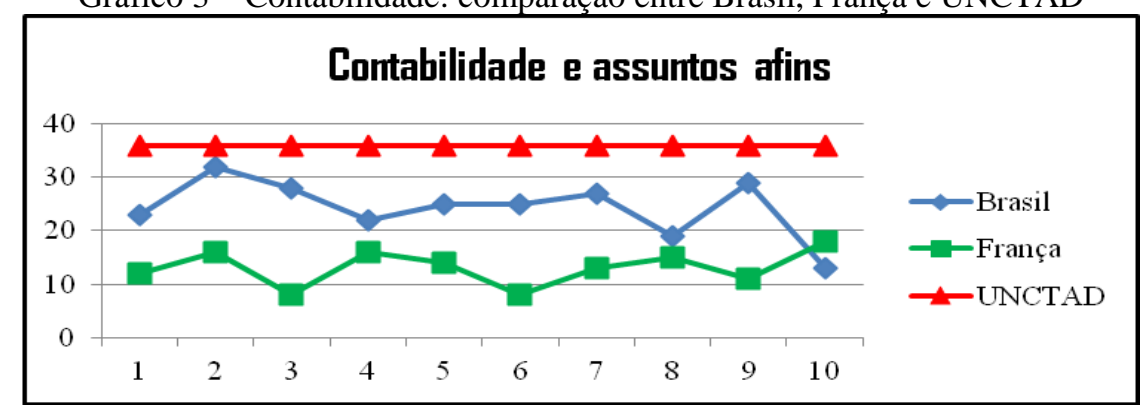

Fonte: dados da pesquisa 2015.

Gráfico 4 - Conhecimentos gerais: comparação entre Brasil, França e UNCTAD

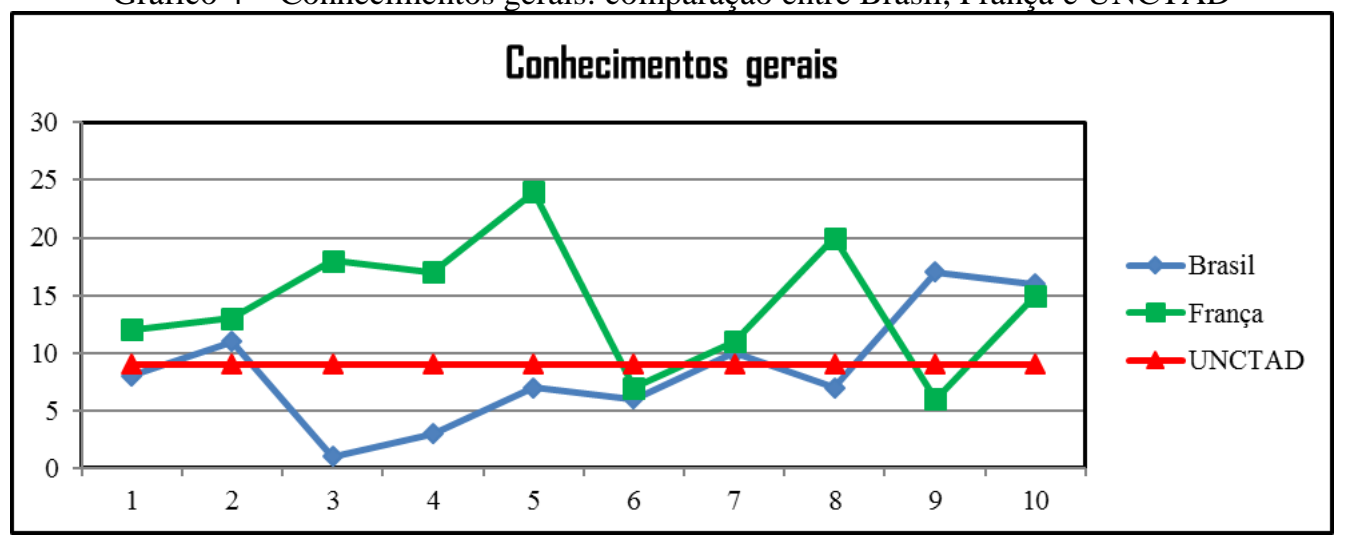

Fonte: dados da pesquisa 2015.

As relações entre as três curvas de cada um dos gráficos de 1 a 4 foram resumidas esquematicamente de duas formas: numérica, na Tabela 4, e em barras, no Gráfico 5. Com isso, pode-se comparar de modo mais abrangente o grau de similaridade, em cada país, entre seus currículos acadêmicos e os blocos de conhecimento do CM. A proximidade é medida em pontos percentuais.

Tabela 4 - Médias dos totais de disciplinas em cada universidade, por bloco de conhecimento: proporções do Brasil, da França e da UNCTAD

\begin{tabular}{|l|r|r|r|c|c|c}
\hline BLOCOS DE CONHECIMENTOS & BRASIL & FRANÇA & UNCTAD & Prox. Brasil & Prox. França & Prox. Unctad \\
\hline \hline 1. Conhecimentos administrativos e organizacionais & 10 & 21 & 22 & $45 \%$ & $95 \%$ & $100 \%$ \\
\hline 2. Tecnologia de informação & 2 & 4 & 5 & $40 \%$ & $80 \%$ & $100 \%$ \\
\hline 3. Conhecimentos de Contabilidade e assuntos afins & 24 & 13 & 36 & $67 \%$ & $36 \%$ & $100 \%$ \\
\hline 4. Conhecimentos gerais & 8 & 14 & 9 & $89 \%$ & $156 \%$ & $100 \%$ \\
\hline MÉDIA TOTAL DAS DISCIPLINAS & \multicolumn{1}{|c|}{44} & \multicolumn{1}{|l|}{52} & 72 & $61 \%$ & $72 \%$ & $100 \%$ \\
\hline
\end{tabular}

Fonte: dados da pesquisa 2015. 
Gráfico 5 - Grau de semelhança com o CM: comparação entre os países

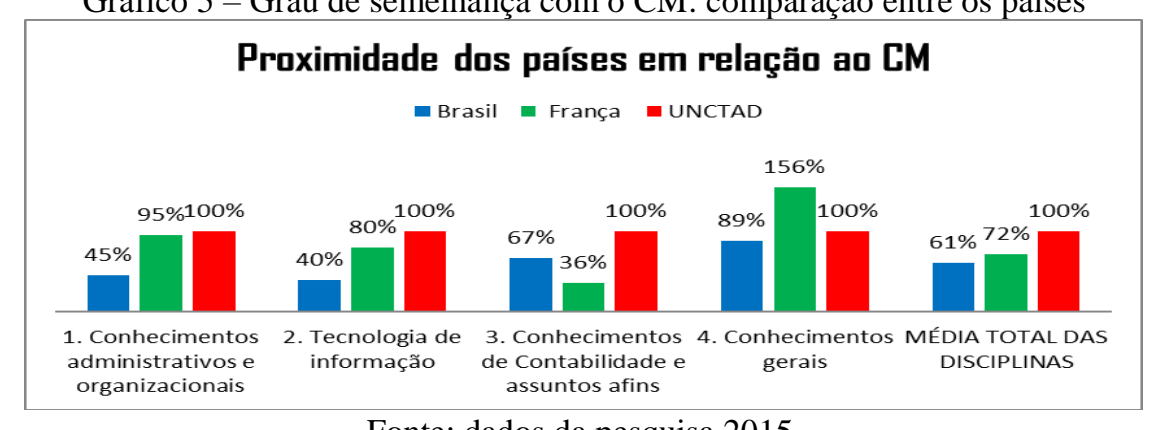

Fonte: dados da pesquisa 2015.

Considerando o bloco de conhecimentos administrativos e organizacionais, a França está mais próxima do documento da UNCTAD, com praticamente $95 \%$ no grau de similaridade. Nesse bloco, o Brasil demonstrou uma proximidade de $45 \%$.

No que diz respeito ao conhecimento de tecnologia de informação, a França se destacou ainda mais próxima do documento da UNCTAD com grau de similaridade de $80 \%$. O resultado para o Brasil foi de $40 \%$.

No tocante ao bloco de conhecimentos de contabilidade e assuntos afins, o Brasil se destacou com maior grau de similaridade em relação ao documento sugerido pela UNCTAD, ou seja, praticamente $67 \%$.

Por fim, no que tange ao bloco de conhecimentos gerais, a França ultrapassou o conteúdo programático mínimo sugerido pela ISAR da UNCTAD. Isso é devido principalmente à predominância de disciplinas tais como língua inglesa, espanhola, psicologia, metodologia de pesquisa, sociologia, capacitação profissional, projetos, espaço europeu, mapa, relatório de estágio, metodologia profissional etc. em quase todas as universidades francesas analisadas. Vale descartar que essa percentagem elevada é devida a quatro universidades $(3,4,5$ e 8 , conforme Tabela 2) que apresentaram um grande numero de disciplinas nesse bloco de conhecimento. O numero elevado de disciplinas dessas universidades tiveram repercussões sobre a média global da França. O Brasil mostrouse com $89 \%$ de similaridade nesse bloco.

\section{CONCLUSÃO}

Este trabalho teve como objetivo investigar, na matriz curricular dos cursos de Ciências Contábeis de universidades francesas e brasileiras, similaridades com o CM sugerido pelo ISAR da UNCTAD. Para tanto, foram coletados os componentes curriculares presentes no website de cada universidade. A amostra final foi composta por 20 universidades, sendo 10 brasileiras e 10 francesas. 
De forma genérica, a França revelou-se mais próxima do documento sugerido pela UNCTAD com $72 \%$ de similaridades. O Brasil apresentou um grau de similaridade de $61 \%$. Levando em consideração o bloco de conhecimentos administrativos e organizacionais, a França destacou-se com maior similaridade, atingindo $95 \%$, enquanto o Brasil ficou em $45 \%$. No que se refere ao bloco de tecnologia de informação, a França mostrou-se mais próxima do $\mathrm{CM}$ com um grau de similaridade de $80 \%$. No que diz respeito ao bloco de contabilidade e assuntos afins, o Brasil destacou-se como mais próximo do documento da UNCTAD com $67 \%$ de similaridade. Em relação ao bloco de conhecimentos gerais, que tem uma visão mais abrangente, indo além das disciplinas da área contábil e incorporando as disciplinas de filosofia, história, sociologia e principalmente línguas estrangeiras, ambos os países estão próximos.

Vale ressaltar que esses achados devem ser interpretados com certa prudência, tendo em vista que os dois países adotam um sistema educacional diferente. Além disso, o modelo adotado na França se caracteriza por uma formação do contador pautada em conhecimentos mais aprofundados de Administração e, mais particularmente, de Economia. Nesse contexto, é importante frisar que, na
França, não existe curso autônomo de graduação em Ciências Contábeis como no Brasil. Lá existe graduação em Ciências Econômicas e Gestão, sendo uma das especialidades de Gestão a Contabilidade. Dessa forma, durante a graduação na França, os estudantes de Economia e Gestão cursam do semestre 1 ao semestre 4 as mesmas disciplinas. É a partir do semestre 5 que cada aluno decide se vai se graduar em Economia ou em Gestão (Contabilidade). Tal fato permite ao formando de Contabilidade adquirir conhecimentos pesados e sólidos de economia (incluindo macroeconomia), funcionamento do mercado, matemática, estatística etc. Esse fato foi observado no bloco de conhecimentos organizacionais, em que a França se destacou com maior similaridade (95\%).

Desse modo, tratando-se de uma pesquisa exploratória, tais resultados podem oferecer indícios sobre as diferenças na Educação Contábil entre os países. É importante relembrar que este estudo não tem nenhuma intenção de classificar as universidades quanto à qualidade do ensino, mas apenas comparar as matrizes curriculares em relação ao CM. Assim o fato de uma universidade ser próxima de tal modelo internacional não significa que é melhor. Com base nos aspectos até aqui analisados, os achados encontrados e interpretados demonstraram 
que as matrizes curriculares das investigar o conteúdo de cada componente

instituições dos países em questão estão e considerar as cargas horárias das próximas do CM. Como futura pesquisa, disciplinas.

sugere-se, além de ampliar a amostra, 


\section{REFERÊNCIAS}

BONK, Curtis Jay; SMITH, G. Stevenson. Alternative instructional strategies for creative and critical thinking in the accounting curriculum. Journal of Accounting Education, v. 16, n. 2, p. 261-293, 1998.

CALHOUN, C.; WALSH, M. UNFs Accounting Curriculum versus the United Nationss Global Curriculum and the ACCA Curriculum: A Comparison. Accounting \& Business, 2000 .

CAVALCANTE, Danival Sousa et al. Adequação dos currículos dos cursos de Contabilidade das universidades federais brasileiras ao Currículo Mundial de Contabilidade e o desempenho no Enade. Pensar Contábil, v. 13, n. 50, 2011.

CZESNAT, Aline Oliveira; CUNHA, Jacqueline Veneroso Alves da; DOMINGUES, Maria José Carvalho de Souza. Análise comparativa entre os currículos dos cursos de Ciências Contábeis das universidades do estado de santa Catarina listadas pelo MEC e o Currículo Mundial proposto pela ONU/UNCTAD/ISAR. Gestão \& Regionalidade, v. 25, n. 75, 2009.

ERFURTH, Alfredo Ernesto; DOMINGUES, Maria José Carvalho de Souza. Currículo Mundial e o ensino de Contabilidade: estudo dos cursos de graduação em Ciências Contábeis em instituições de ensino superior brasileiras e argentinas. Contexto, v. 13, n. 23, p. 47-60, 2013.

FRANCO, Hilário. A Contabilidade na Era da Globalização. São Paulo: Atlas, 1999.

GIL, ANTONIO CARLOS. Como elaborar projetos de pesquisa. 4. ed. São Paulo: Atlas, 2007.

HENDRIKSEN, E. S.; BREDA, Van M. Teoria da Contabilidade. Tradução de Antônio Zoratto Sanvicente. (1. ed.) $11^{\circ}$ reimpr. São Paulo: Atlas 2014.

HOPWOOD, Anthony G. On trying to study accounting in the contexts in which it operates. Accounting, organizations and society, v. 8, n. 2-3, p. 287-305, 1983.

LEITE, C. E. B. A Evolução das Ciências Contábeis no Brasil. 1. ed. Rio de Janeiro: FGV, 2005 . 
LEITE, J. S. J. Normas contábeis internacionais: uma visão para o futuro. Cadernos da

Faceca, n. 1, p. 51-65, Campinas, janeiro/ junho 2002.

MARTINS, E. Normas internacionais x brasileiras: transformando a história contábil. Revista ANEFAC, São Paulo, n. 96, jun 2004.

MEYER, John W.; SCOTT, W. Richard. The organization of societal sectors: propositions and early evidence. The new institutionalism in organizational analysis, p. 108-140, 1991.

MULATINHO, C. E. S. Educação contábil: um estudo comparativo das grades curriculares e da percepção dos docentes dos cursos de graduação das universidades federais da Paraíba, Pernambuco e Rio Grande do Norte, referentes ao Programa Mundial de Estudos em Contabilidade proposto pelo ISAR/UNCTAD/ONU. Dissertação (Mestrado em Ciências Contábeis) - Universidade de Brasília, da Universidade Federal da Paraíba, da Universidade Federal de Pernambuco e da Universidade Federal do Rio Grande do Norte, Recife, PE, Brasil 2007.

NIYAMA, J. K. Contabilidade internacional. 1. ed. 5. reimpr. São Paulo: Atlas 2008.

RICCIO, E. L.; SAKATA, M. C. G. Evidências da globalização na educação contábil: estudo das grades curriculares dos cursos de graduação em universidades brasileiras e portuguesas. Revista Contabilidade \& Finanças, 15(35), 35-44 2004.

RIZVI, Fazal et al. Difference, globalisation and the internationalisation of curriculum. The Australian Universities' Review, v. 41, n. 2, p. 7, 1998.

RIPOLL, V.; ROSA, L. La formación del profesional de contabilidad frente a las necesidades del mercado: comparación del caso brasileño, español y portugués. Revista del Instituto Internacional de Costos, p. 1-22, 2010.

SANTOS, Alexandre Corrêa; DOMINGUES, Maria José Carvalho de Souza; RIBEIRO, Maria José. Nível de Similaridade das Matrizes Curriculares dos Cursos de Ciências Contábeis das Instituições Paranaenses Listadas no MEC, Ao Currículo Mundial. Registro Contábil, v. 4, n. 3, p. 105-127, 2013.

SEGANTINI, Giovanna Tonetto et al. Uma análise crítica entre os currículos dos cursos de Ciências Contábeis nos países do Mercosul e o proposto pela ONU/UNCTAD/ISAR. Revista Evidenciação Contábil \& Finanças, v. 1, n. 1, p. 85-98, 2013. 
SHIXIU, Z. Como a China considera e participa da globalização. 2008. Disponível em <http://www.redem.buap.mx/word/2001 zhou.doc>. Acesso em: 01 nov. 2014.

TCHEOU, H. Avaliação do ensino de Contabilidade nos cursos de administração de empresas na cidade de São Paulo. 2002. Dissertação (Mestrado em Controladoria e Contabilidade Estratégica) - Faculdade de Ciências Econômicas de São Paulo, Fundação Escola de Comércio Álvares Penteado, São Paulo, 2002.

UNCTAD (United Nations Conference On Trade And Development). Guideline for a global accounting curriculum and other qualification requirements. Genebra: 1999. Disponível em: <http://unctad.org/en/Docs/c2isard5.en.pdf>. Acesso em: 05 out. 2017.

Revised Model Accounting Curriculum (MC). Genebra: 2003. Disponível em: <http://unctad.org/en/Docs/c2isar21_en.pdf>. Acesso em: 05 out. 2017. 